\title{
Depletion of the Ozone Layer in the 21st Century
}

\author{
Martin Dameris*
}

atmospheric chemistry · chlorofluorocarbons . climate change $\cdot$ nitrogen oxides $\cdot$ ozone

\section{$T_{\mathrm{o}}$} placed on the back burner in public discussions of climate change. Since the mid-1980s it has been known that primarily chlorofluorocarbons (CFCs) and also halocarbons (compounds where carbon atoms are linked to fluorine, chlorine, bromine, or iodine, but also to hydrogen) are mainly responsible for the destruction of the ozone layer in the stratosphere (atmospheric layer at an altitude of 12 to $50 \mathrm{~km}$ ). Hence the production and usage of these substances were nearly fully prohibited in the Montreal Protocol (1987) and in subsequent agreements. As a consequence of these international treaties the strong increase of CFC concentrations in the troposphere (atmospheric layer up to an altitude of about $12 \mathrm{~km}$ ) has halted (Figure 1). Since the mid-1990s the amount of CFCs in the troposphere has been decreasing. As a result, a reduction in the stratospheric chlorine concentration has been observed in recent years. Therefore it is expected that the ozone layer will increase in thickness and that the ozone hole over the Antarctic will disappear. ${ }^{[1]}$ Owing to the long lifetimes of CFCs in the atmosphere, it will take until about the middle of this century before the stratospheric chlorine level returns to the values measured in the 1960s.

One could conclude that the ozone layer will fully recover by the middle of this century. However, the reconstruction of the ozone layer also depends on other atmospheric processes which complicate a reliable assessment of the future evolution. As a result of increased concentrations of well-mixed greenhouse gases in the atmosphere (e.g. $\mathrm{CO}_{2}, \mathrm{CH}_{4}$, and $\mathrm{N}_{2} \mathrm{O}$ ), the troposphere warms (greenhouse effect) and the stratosphere cools (enhanced emission of long-wavelength thermal radiation). A multitude of chemical reactions in the atmosphere depend on the predominating temperature. For example, the ozone content in the middle and upper stratosphere increases with decreasing temperature since the most important ozone-destroying reactions (homogeneous gasphase reactions) slow down. ${ }^{[2]}$ In contrast, lower temperatures in the lower stratosphere over the polar regions cause stronger ozone depletion as a result of heterogeneous chemical reactions on very cold cloud particles. ${ }^{[1]}$

[*] Prof. Dr. M. Dameris

Deutsches Zentrum für Luft- und Raumfahrt Institut für Physik der Atmosphäre Oberpfaffenhofen, 82234 Wessling (Germany)

E-mail:martin.dameris@dlr.de

Homepage: http://www.dlr.de/ipa)

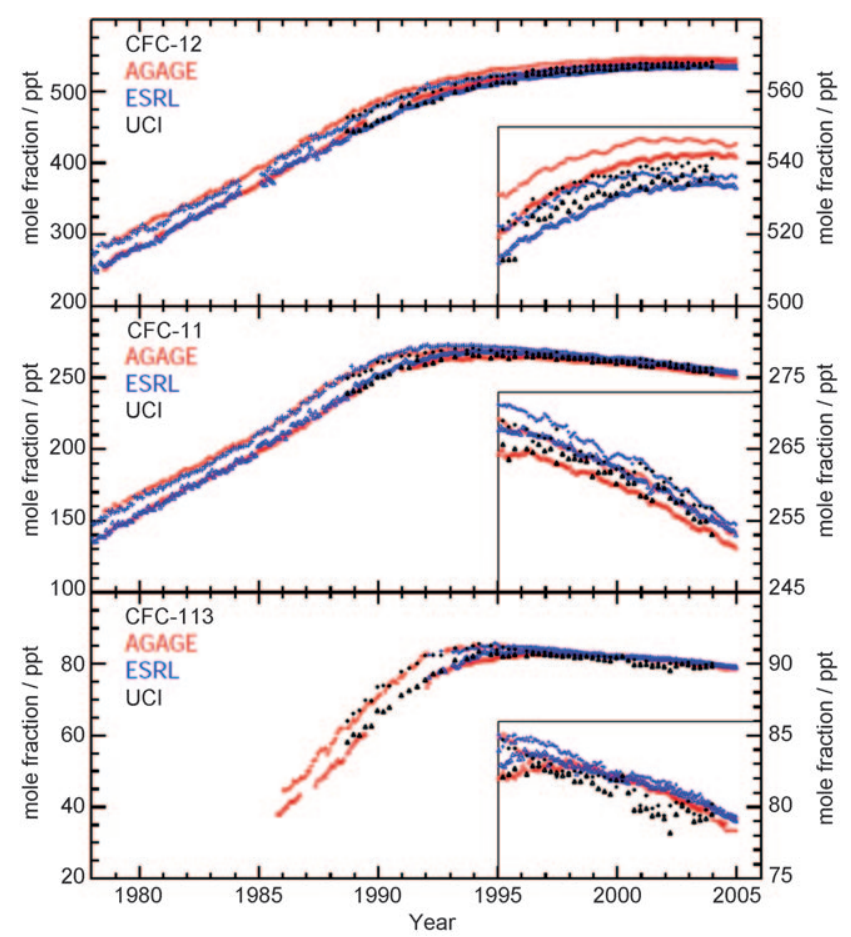

Figure 1. Hemispheric monthly mean values of tropospheric mixing ratios (in ppt $=$ parts per trillion $=10^{-12}$ ) of the most important CFCs (CFC-12 $=\mathrm{CF}_{2} \mathrm{Cl}_{2}, \mathrm{CFC}-11=\mathrm{CFCl}_{3}$, and CFC-113= $\mathrm{Cl}_{2} \mathrm{FC}-\mathrm{CClF}_{2}$ ). Crosses indicate measured values for the northern hemisphere, triangles for the southern hemisphere. Recent results are shown in the insets (Taken from Figure 1-1 in Ref. [1].) AGAGE=Advanced Global Atmospheric Gases Experiment, ESRL = Earth System Research Laboratory, $\mathrm{UCI}=$ University of California, Irvine.

As a consequence of changes in the thermal structure of the atmosphere, dynamic processes in the atmosphere are changing and impacting the distribution of the trace gases that have longer lifetimes. ${ }^{[3-6]}$ So far, studies with numerical atmospheric models, so-called climate-chemistry models (CCMs), have not provided a consistent picture with regard to the speed of ozone recovery. ${ }^{[1]}$ Results derived from model simulations agree on the point that the regeneration of the ozone layer will develop with regional differences. Model calculations indicate that, overall, processes related to climate change will cause an accelerated recovery of the ozone layer. Most CCMs predict a return to the ozone levels observed in the 1960s clearly before the middle of this century (Figure 2). 
Total Ozone Anomaly $\left(60^{\circ} \mathrm{N}-60^{\circ} \mathrm{S}\right)$

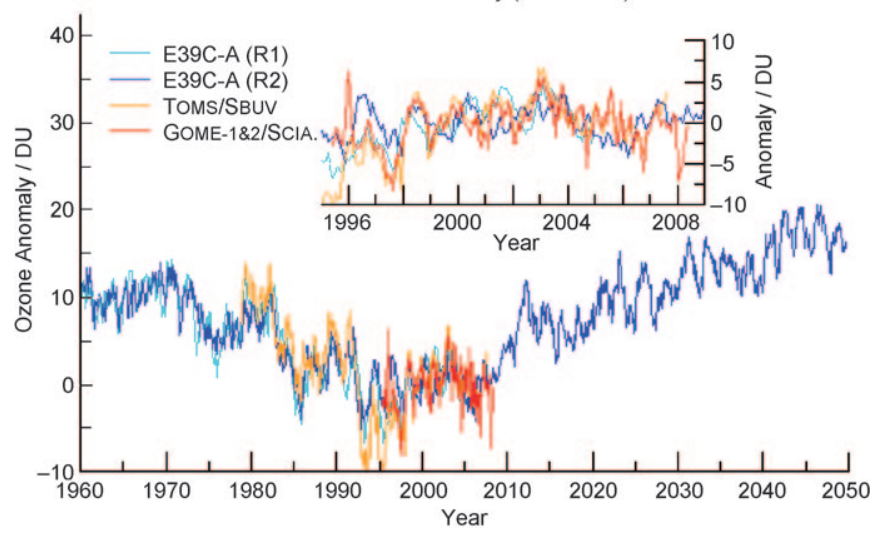

Figure 2. Mean values of total ozone anomalies (in Dobson units, DU) for the geographical region from $60^{\circ} \mathrm{N}$ to $60^{\circ} \mathrm{S}$. The mean annual cycle for the years from 1995 to 2004 was removed from each single time series. The orange and red curves represent measurements derived from satellite instruments. The blue curves are showing results derived from numerical simulations with a climate-chemistry model (E39C-A). The reduction of the thickness of the stratospheric ozone is apparent in the 1980s and 1990s as well as the predicted increase until to the middle of this century. The inset shows parts of the time series in extension. (Updated version of Figure 9 in Ref. [7].)

In a recent paper published in Science, Ravishankara and co-workers investigated another important aspect which will obviously have an impact on the future evolution of the ozone layer and which will complicate reliable predictions even more. ${ }^{[8]}$ They studied the role of laughing gas $\left(\mathrm{N}_{2} \mathrm{O}\right)$ in connection with ozone depletion. $\mathrm{N}_{2} \mathrm{O}$ emissions near the Earth's surface are the most important source of nitric oxide $\left(\mathrm{NO}_{x}\right)$ in the stratosphere, although only about $10 \%$ of the released $\mathrm{N}_{2} \mathrm{O}$ is converted into $\mathrm{NO}_{x}\left(=\mathrm{NO}+\mathrm{NO}_{2}\right)$. $\mathrm{NO}_{x}$ largely contributes to the depletion of stratospheric ozone. ${ }^{[9]}$ Laughing gas comes from natural sources (e.g. from the ocean, tropical forests) as well as anthropogenic sources (e.g. emissions from cultivated land, industrial processes, and the burning of fossil fuels, biomass, and biofuels). ${ }^{[10]}$ Like CFCs, $\mathrm{N}_{2} \mathrm{O}$ is very stable in the troposphere and has a mean lifetime of about 120 years. As mentioned before, $\mathrm{N}_{2} \mathrm{O}$ is also an important greenhouse gas and is therefore regulated under the Kyoto Protocol.

Until now $\mathrm{N}_{2} \mathrm{O}$ has not been rated or regulated as an ozone-depleting substance in connection with the Montreal Protocol, although the current emission of laughing gas exceeds that of any other ozone-destroying species, and most likely this will be the case for the rest of the 21st century. The ozone-destroying potential of $\mathrm{N}_{2} \mathrm{O}$ is very well known. Ravishankara and co-workers concluded that the depletion of ozone by $\mathrm{NO}_{x}$ dominates the chemical control of ozone in the middle stratosphere (approximately from 25 to $40 \mathrm{~km}$ ). Nitric oxides are destroying ozone largely in the region of maximum ozone concentrations, and that is why the reduction of ozone by nitric oxide is very efficient. In addition, it must be considered that nitric oxides deactivate chlorine radicals by forming chlorine nitrate $\left(\mathrm{ClONO}_{2}\right)$ and therefore reduce the contribution of chlorine to ozone destruction.
The investigations by Ravishankara and co-workers show that the ozone-depleting potential of laughing gas (per emitted unit mass) should increase by about $50 \%$ when the amount of stratospheric chlorine returns to preindustrial concentrations. Although the $\mathrm{N}_{2} \mathrm{O}$ 's ozone destructiveness is only about one-sixtieth of that of CFC-11, the large anthropogenic emissions of $\mathrm{N}_{2} \mathrm{O}$ are the most important single anthropogenic source of ozone-destroying substances today. Today's global emission of $\mathrm{N}_{2} \mathrm{O}$ arising from human activities is about 10.5 million metric tons per year. In comparison: approximately 1 million metric tons per year of all CFCs were released at the end of the 1980s, that is, at the peak of their emissions. Recent estimates of expected future emissions of $\mathrm{N}_{2} \mathrm{O}$, even under very stringent regulations for greenhousegas reduction, continue to show that emissions of laughing gas will unlikely be lower than they are today. ${ }^{[11]}$ Here it must be mentioned that the estimates of expected future $\mathrm{N}_{2} \mathrm{O}$ emissions are highly uncertain. But if anthropogenic emissions of $\mathrm{N}_{2} \mathrm{O}$ continue unabatedly, by the middle of this century they could represent about $30 \%$ of CFC's ozonedepleting potential at the time of maximum emissions.

It can be concluded that the regulation of $\mathrm{N}_{2} \mathrm{O}$ levels in the atmosphere is not only important for the protection of Earth's climate (Kyoto Protocol) but also for the future evolution of the stratospheric ozone layer (Montreal Protocol). A reduction of $\mathrm{N}_{2} \mathrm{O}$ emissions would decrease the anthropogenic greenhouse effect and it would have a positive impact on the recovery of the ozone layer.

Based on these findings it is apparent that an understanding of changes in the atmosphere is not sufficient to consider isolated facts. Changes in the climate and the chemical composition of the atmosphere are interrelated. Dynamic, physical, and chemical processes affect each other, in part in a very complex manner. Therefore, surprising developments cannot be excluded in the future. As a result of the various factors impacting atmospheric behavior and the complex interactions of atmospheric processes, it remains a tremendous challenge for atmospheric science to provide reliable predictions of future climate change and the evolution of the stratospheric ozone layer.

Received: November 10, 2009

Published online: December 8, 2009

[1] WMO (World Meteorological Organisation), Global Ozone Research and Monitoring Project 2007, Report No. 50, p. 572 (ISBN 978-92-807-2756-2).

[2] J. Haigh, J. Pyle, Q. J. R. Meteorol. Soc. 1982, 108, 551-574.

[3] N. Butchart, A. A. Scaife, M. Bourqui, J. de Grandpré, S. H. E. Hare, J. Kettleborough, U. Langematz, E. Manzini, F. Sassi, K. Shibata, D. Shindell, M. Sigmond, Climate Dyn. 2006, 27, 727 741.

[4] N. Butchart, I. Cionni, V. Eyring, T. G. Shepherd, D. W. Waugh, H. Akiyoshi, J. Austin, C. Brühl, M. P. Chipperfield, E. Cordero, M. Dameris, R. Deckert, S. Dhomse, S. M. Frith, R. R. Garcia, A. Gettelman, M. A. Giorgetta, D. E. Kinnison, F. Li, E. Mancini, C. McLandress, S. Pawson, G. Pitari, D. A. Plummer, E. Rozanov, F. Sassi, J. F. Scinocca, K. Shibata, B. Steil, W. Tian, J. Climate 2009, submitted.

[5] R. Deckert, M. Dameris, Geophys. Res. Lett. 2008, 35, L10813. 
[6] R. R. Garcia, W. J. Randel, J. Atmos. Sci. 2008, 65, 2731-2739.

[7] D. G. Loyola, R. M. Coldewey-Egbers, M. Dameris, H. Garny, A. Stenke, M. Van Roozendael, C. Lerot, D. Balis, M. Koukouli, Int. J. Remote Sensing 2009, 30, 4295-4318.

[8] A. R. Ravishankara, J. S. Daniel, R. W. Portmann, Science 2009, 326, $123-125$.

[9] P. J. Crutzen, Q. J. R. Meteorol. Soc. 1970, 96, 320-327.
[10] IPCC (Intergovernmental Panel on Climate Change), Climate Change 2001, p. 881.

[11] D. P. van Vuuren, M. G. J. den Elzen, P. L. Lucas, B. Eickhout, B. J. Strengers, B. van Ruijven, S. Wonink, R. van Houdt, Clim. Change 2007, 81, 119-159; Minireview on the binding and activation of $\mathrm{N}_{2} \mathrm{O}$ by transition-metal centers: W. B. Tolman, Angew. Chem., DOI: 10.1002/ange.200905364; Angew. Chem. Int. Ed. DOI: 10.1002/anie.200905364.

\section{Accelerate your chemical reactions with a new and improved resource.}

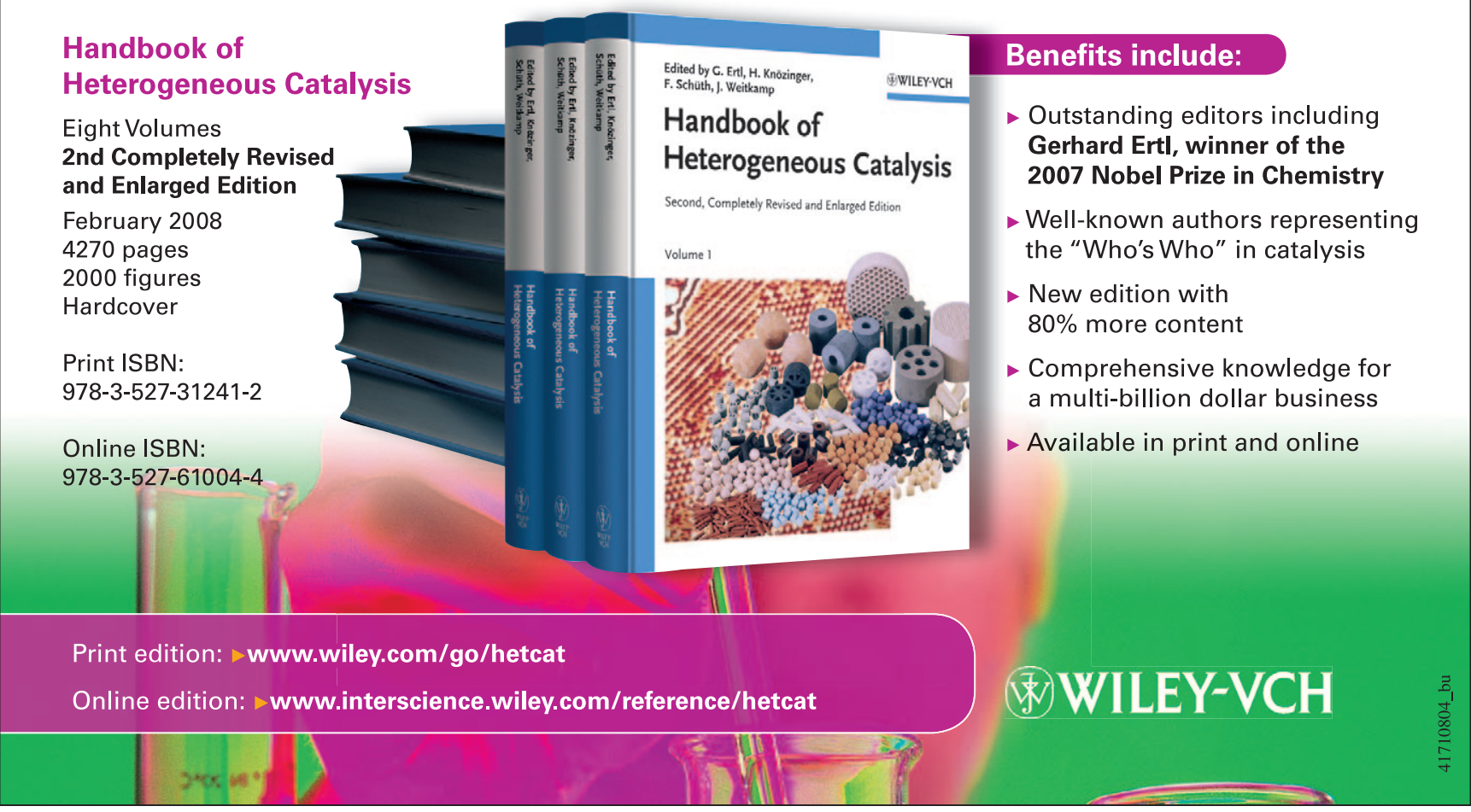

